\title{
Análisis de la opinión de los hogares sobre la gestión de los residuos sólidos domiciliarios en Bogotá*
}

\author{
Recibido: 23 de marzo de 2019 • Aprobado: 11 de abril de 2019 \\ https://doi.org/10.22395/seec.v22n52a5 \\ María del Pilar Sánchez-Muñoz** \\ José Gabriel Cruz Cerón*** \\ José Jardani Giraldo Uribe****
}

\section{RESUMEN}

Hacer un análisis sobre la opinión que los hogares tienen de la gestión de los residuos sólidos en su ciudad, permite enfocar las estrategias de intervención para lograr los objetivos de política. Este documento presenta los hallazgos sobre la opinión de los hogares localizados en la zona que operaba hasta inicios de 2018 la empresa Aguas de Bogotá S. A. ESP, sobre la gestión de los residuos sólidos domiciliarios. Se utiliza la estadística descriptiva, se aplicaron 384 encuestas. Se concluye que hay una tendencia en la ciudad a la falta de gobernanza ambiental y se hace necesaria una masificación de la sensibilización sobre la importancia de hacer separación en fuente y el uso adecuado de los contenedores y de las bolsas plásticas.

\section{PALABRAS CLAVE}

Residuos sólidos; reciclaje; instituciones; desarrollo sostenible.

\section{CLASIFICACIÓN JEL}

Q53, P48, Q01.

\section{CONTENIDO}

Introducción; 1. Desarrollo sostenible y residuos sólidos; 2. Gestión de los residuos sólidos domiciliarios en Bogotá; 3. Metodología; 4. Resultados; 5. Conclusiones; Bibliografía.

\footnotetext{
Este artículo de investigación es resultado del proyecto Modelo socioecológico para los residuos sólidos domiciliarios aprovechables en Bogotá D.C., desarrollado en el marco de las disertaciones que se realizaron en el Doctorado en Desarrollo Sostenible de la Universidad de Manizales sobre el tema de residuos sólidos. Adicionalmente contó con tiempo dispuesto por la Universidad Surcolombiana para la elaboración de esta producción académica.

. Economista, Universidad Católica de Colombia, Bogotá, Colombia. Magíster en Economía, Universidad Nacional de Colombia, Bogotá, Colombia. Doctora en Desarrollo Sostenible, Universidad de Manizales, Caldas, Colombia. Docente Facultad de Ciencias Contables, Económicas y Administrativas, Universidad de Manizales, Caldas, Colombia y de la Facultad de Economía de la Universidad del Rosario, Bogotá, Colombia. Investigadora del grupo de investigación Economía y Desarrollo Humano de la Universidad de La Salle, Bogotá, Colombia. Correo electrónico: mariad.sanchez@urosario.edu.co

... Ingeniero Agrónomo, Universidad Nacional de Colombia, Palmira, Colombia. Magíster en Administración Industrial, Universidad del Valle, Cali, Colombia. Doctor en Ciencias Económicas, Universidad de La Habana, La Habana, Cuba. Profesor titular de la Universidad de Caldas, Manizales, Colombia. Investigador del grupo Ceres, Universidad de Caldas, Caldas, Colombia. Correo electrónico: gabocruzc@gmail.com

.... Economista, Universidad Libre, Pereira, Colombia. Magíster en Administración Económica y Financiera, Universidad Tecnológica de Pereira, Pereira, Colombia. Doctor en Desarrollo Sostenible, Universidad de Manizales, Caldas, Colombia. Docente de tiempo completo de la Universidad Surcolombiana, Huila, Colombia. Investigador del grupo Iguaque. Correo electrónico: jose.giraldo@usco.edu.co
} 


\title{
ANALYSIS OF THE OPINION ON HOMES SOLID RESIDUES MANAGEMENT IN BOGOTÁ
}

\begin{abstract}
Analyzing the opinion at homes on the management of solid residues in your city allows the narrowing of the intervention strategies for the achieving of political goals. This document presents the findings on the opinion about the management of solid home residues of homes located in the areas in which the company Aguas de Bogotá S. A. ESP operated until the beginnings of 2018. This article concludes that in the city there is a tendency inclined towards the lack of environmental governance and that a massification of the sensitization about the importance of separating in the source is necessary, as well as adequate use of bags and containers.
\end{abstract}

\section{KEYWORDS}

Solid residues; recycling; institutions; sustainable development.

\section{JEL CODE}

Q53, P48, Q01.

\section{CONTENTS}

Introduction; 1. Sustainable development and solid residues; 2. Management of home solid residues in Bogota; 3. Methodology; 4. Results; 5. Conclusions; Bibliography.

\section{ANÁLISE DA OPINIÃO DOS LARES SOBRE A GESTÃO DOS RESÍDUOS SÓLIDOS RESIDENCIAIS EM BOGOTÁ*}

\section{RESUMO}

A análise da opinião advinda dos lares quanto à gestão dos resíduos sólidos em sua cidade permite elaborar estratégias de intervenção para atingir objetivos de política. Este documento apresenta os achados sobre a opinião da população de moradias localizadas na área que a empresa Aguas de Bogotá S. A. ESP. operava até o início de 2018 sobre a gestão dos resíduos residenciais. É utilizada a estatística descritiva e aplicado questionário a 384 participantes. Conclui-se que há uma tendência na cidade para a falta de governança ambiental e que é necessária uma massificação da sensibilização acerca da importância de fazer a separação do lixo na fonte, além do uso adequado das lixeiras e dos sacos plásticos.

\section{PALAVRAS-CHAVE}

Resíduos sólidos; reciclagem; instituições; desenvolvimento sustentável.

\section{CLASSIFICAÇÃO JEL} Q53, P48, Q0 1 .

\section{CONTEÚDO}

Introdução; 1. Desenvolvimento sustentável e resíduos sólidos; 2. Gestão dos resíduos sólidos residenciais em Bogotá; 3. Metodologia; 4. Resultados; 5. Conclusões; Bibliografia. 


\section{INTRODUCCIÓN}

Los residuos sólidos generados por los hogares son, en parte, dispuestos en el relleno sanitario y, en parte, potencialmente reutilizables como materia prima por la industria. Sin embargo, de acuerdo con la Unidad Administrativa Especial de Servicios Públicos (Uaesp) de la Secretaría del Hábitat de la Alcaldía Mayor de Bogotá (2017), la proporción de residuos aprovechables en Bogotá es del 14 \%. Asimismo, existe otro agravante que no es particular de la ciudad pero que sí preocupa por los efectos que conlleva y tiene que ver con la institucionalidad en la gestión de los residuos sólidos, dado que las estrategias propuestas para alcanzar los objetivos de política tienden a no generar los resultados esperados.

El objetivo de esta investigación es el de conocer la opinión de los hogares que se encuentran localizados en la zona operada por Aguas de Bogotá S. A. ESP., como área representativa de la ciudad, sobre la gestión de los residuos sólidos domiciliarios. Para ello, se utiliza la estadística descriptiva, se aplicaron 384 encuestas a los hogares de las 12 localidades que recibían el servicio de recolección de residuos sólidos por parte de este operador público hasta el 11 de febrero de 2018. Estas localidades son: Engativá, Fontibón, Barrios Unidos, Teusaquillo, Chapinero, Los Mártires, Santa Fe, Antonio Nariño, Rafael Uribe, Candelaria, San Cristóbal y Usme, las cuales comprendían el 52 \% del territorio y abarcaban a 1.431 .744 suscriptores. Estas 12 localidades fueron seleccionadas por su ubicación y representatividad geográfica correspondiente a más de la mitad de Bogotá.

El documento consta de ocho partes incluyendo la presente introducción. En la segunda, se ofrecen algunos referentes sobre el desarrollo sostenible, los residuos sólidos domiciliarios y cómo se interrelacionan con los referentes teóricos utilizados como el territorio, las instituciones y la gobernanza ambiental. En la tercera parte, se contextualizan los elementos de estos desechos para la ciudad de Bogotá. En la cuarta, se describe la metodología; en la quinta parte se presentan los resultados del estudio. Finalmente, se encuentran las conclusiones producto de la investigación y los referentes bibliográficos.

\section{DESARROLLO SOSTENIBLE Y RESIDUOS SÓLIDOS}

Desde el Informe Brundtland se estableció que "el desarrollo sostenible es aquel que satisface las necesidades presentes sin comprometer la capacidad de las futuras generaciones para satisfacer las propias" (Comisión Mundial sobre Medio Ambiente y el Desarrollo, 1987, p. 23). En otras palabras, y siguiendo a López et al., (2006) el acceso a las oportunidades de las generaciones actuales no puede sacrificar la disponibilidad de recursos para satisfacer las necesidades de las generaciones futuras. 
Adicionalmente, Leff $(1995,2010)$ sostiene que es indispensable incorporar criterios culturales y tecnológicos a un paradigma alternativo de producción que vaya mucho más allá de la racionalidad económica dominante. Para Leff (1995), el desarrollo sostenible depende de las características propias de los ecosistemas en función de los recursos bióticos, los servicios ambientales y de las ideologías culturales y políticas de la sociedad. En el caso del manejo de residuos sólidos, se debe propender por la prestación de un servicio ambiental, más que prestar un servicio logístico de traslado de materiales del sitio donde se generan los desechos a su disposición final. Además, es necesario adquirir conciencia de un consumo responsable, que respete el equilibrio de las actividades antrópicas y sus efectos en la naturaleza, para contribuir con el desarrollo sostenible.

Asimismo, la Organización de las Naciones Unidas (2017) en los objetivos de desarrollo sostenible (ODS) estableció metas comunes en temas de agua, aire, suelo, entre otros, para alcanzar mejores condiciones de vida actuales y garantizar la vida de las generaciones futuras, respetando los ecosistemas. Específicamente en lo referente al manejo de residuos sólidos está el objetivo seis de los ODS, el cual plantea metas para "garantizar la disponibilidad de agua y su gestión sostenible y el saneamiento para todos".

La prestación eficiente de los servicios públicos es una oportunidad para que los ciudadanos vivan bien y se fomente el desarrollo. En particular, el manejo adecuado de residuos sólidos puede constituirse en un factor determinante para mejorar las condiciones medioambientales de las ciudades, con repercusiones favorables no solo para el ambiente sino para todos los agentes económicos involucrados en esta actividad.

En este sentido, Villanueva (2011) plantea que se debe promover "la información, la toma de conciencia y el posicionamiento de los ciudadanos y ciudadanas respecto a los problemas generados por nuestro modelo de consumo" (p. 29).

Asimismo, el Plan Nacional de Desarrollo (2014-2018) impulsaba el crecimiento verde, para lo cual se requiere la aplicación de la economía circular. Este concepto se basa en tres principios fundamentales: reducir la cantidad de residuos sólidos generados, reciclar el material potencialmente reutilizable y transformarlo (al utilizarlo como materia prima en la industria). Así, el llamado de Gómez (2017) es a usar los desechos como materia prima y que se generen más negocios y más empleos verdes, que en concordancia con el Plan Nacional de Desarrollo (2018-2022), corresponde a los lineamientos de la economía naranja. 


\subsection{Territorio}

Todo lo anterior se desarrolla en el marco de una territorialidad, porque las relaciones que se encuentran en el entramado de las partes del territorio, las relaciones sociales, económicas, políticas e ideológicas son las que inciden para caracterizar y comprender las manifestaciones reales de las ciudades (Carrasco, 2007).

En palabras de Boisier (1999, p. 7), "la región es un espacio organizado que contiene, en términos reales o en términos potenciales, los factores de su propio desarrollo, con total independencia de escala". Asimismo, para Boisier (1997) cada ciudad tiene sus propias dinámicas porque cada territorio posee características propias que impiden que el desarrollo sea universal, por lo tanto, debe ser interpretado desde las complejidades de lo local .

Igualmente, de acuerdo con Tello (2006) una de las características del desarrollo sostenible en una ciudad es que es posible dimensionar sobre un espacio geográfico limitado a los agentes productivos, a los ciudadanos y al Estado (entendiéndolo como el tipo de organización social y formación institucional). Se plantea, además, que el desarrollo en el territorio' depende de la adecuada intervención del Estado que debe garantizar los mínimos que permitan ampliar las opciones de los habitantes. En este sentido, Panayotou (1996, p. 44) afirma que "el rol del Estado debería cambiar, de uno intervencionista y que distorsiona, a uno que crea marcos institucionales y de política ambiental para el funcionamiento de los mercados de manera eficiente, equitativa y sostenible".

\subsection{Instituciones y residuos sólidos}

Otro soporte teórico que valida el estudio de la gestión de los residuos sólidos es la nueva economía institucional (NEI), porque permite, en palabras de Sánchez y Usaquén (2012, p. 34). "entender la forma en que se relacionan los agentes económicos que conforman el sector de los servicios públicos domiciliarios, como organizaciones del Estado, empresas privadas o mixtas y la comunidad receptora". Para North $(1993$, p.13) las instituciones corresponden a las reglas del juego tanto formales (leyes o normas) como informales (acuerdos y códigos de conducta) que guían la actuación de los individuos. En palabras del autor, "son las limitaciones ideadas por el hombre que dan forma a la interacción humana. Por consiguiente, estructuran incentivos en el intercambio humano, sea político, social o económico". Adicionalmente, tener unas instituciones claras a la hora de gestionar el manejo de los residuos sólidos permite que los objetivos de política pública, para favorecer el desarrollo sostenible, se cumplan porque, según Gandlgruber (2010, p. 18), aceptar una regla implica identificar un conjunto de acciones acordes entre ellas.

De acuerdo con Boisier (1999, p. 21), se entiende el desarrollo como "un proceso local, endógeno, descentralizado, capilar y continuo o discontinuo sobre el territorio". 
De acuerdo con Monroy (2008) las políticas ambientales deben promover una educación consistente para la gestión de residuos sólidos, también deben buscar el buen manejo en la fuente, la menor generación de estos residuos, la promoción de las políticas de producción limpia, un excelente nivel de recolección, transporte en vehículos modernos, buenas estaciones de transferencia y óptimos rellenos sanitarios. Para Martínez y Roca (2013) dentro de la política ambiental se deben utilizar impuestos, si lo que se busca es alcanzar la eficiencia, es decir lograr los objetivos con el menor costo; pero si lo prioritario es la efectividad, lo mejor es hacer una regulación directa.

\subsection{Gobernanza ambiental y residuos sólidos}

En la actualidad se discute sobre las transformaciones que se han evidenciado en las formas como se gobierna y se toman decisiones, dándole el nombre de gobernanza siguiendo a Vergara (2014, p. 89) al análisis de "cómo los actores sociales y políticos encuentran mecanismos de negociación para responder a problemas comunes, vinculando distintas formas de participación y representación en sistemas decisionales públicos y privados".

Cuando se habla de gobernanza, los actores interactúan entre ellos, sin jerarquías, para generar condiciones más favorables y para aumentar las capacidades de todos en la resolución de conflictos a través de la toma de decisiones y la implementación de políticas. Cuando los conflictos o problemáticas están relacionados con el ambiente se habla de gobernanza ambiental. En palabras de Molina (2014, p. 30) esta "se entiende como procesos de toma de decisiones y de ejercicio de autoridad en el ámbito de los bienes públicos, en los cuales interactúan instituciones gubernamentales, empresas privadas y la sociedad civil". En el caso del manejo de residuos sólidos, una gran cantidad de los mismos dispuestos en relleno sanitario afecta el suelo y las aguas subterráneas, razón por la cual es necesaria una política que realmente reduzca la generación de desechos, aumente el uso de aprovechables en la industria y la búsqueda de tecnologías de disposición más amigables con los ecosistemas.

Esta política no solo puede contener reglas de juego formales (instituciones), también requiere enfatizar los valores culturales de todos los actores que participan en el proceso. En otras palabras, hay una tendencia en la ciudad a la falta de gobernanza ambiental en materia de gestión de residuos sólidos y es uno de los elementos que se requiere para generar cambios en las organizaciones y en los ciudadanos quienes deben tomar conciencia de los nefastos efectos de un inadecuado manejo de los desechos. Lo anterior es corroborado por Molina (2013) cuando afirma que se carece de una gobernanza para la gestión adecuada de los residuos sólidos. El 
ciudadano siente como una imposición las instituciones (reglas de juego) ya creadas y su participación se reduce a recepcionar la poca información que el sector posee y que es publicada en medios de comunicación.

\section{GESTIÓN DE LOS RESIDUOS SÓLIDOS DOMICILIARIOS EN BOGOTÁ}

El Decreto 1077 de 2015 define la gestión integral de residuos sólidos como "el conjunto de actividades encaminadas a reducir la generación de residuos, a realizar el aprovechamiento teniendo en cuenta sus características, volumen, procedencia, costos, tratamiento con fines de valorización energética, posibilidades de aprovechamiento y comercialización. También incluye el tratamiento y disposición final de los residuos no aprovechables".

Para autores como Sadeghian et al. (2018) y Zhang, Huang y He (2011), el objetivo principal de la gestión de residuos es la correcta recolección y disposición de los desechos de modo que los costos y los niveles de contaminación se reduzcan al mínimo. No obstante, en esta investigación se conoció la opinión de los hogares, que son generadores de residuos sólidos y sobre quienes la política ambiental relacionada con estos desechos debe dirigir las estrategias que permitan incorporar nuevamente a diferentes procesos productivos, en el marco de la economía circular, los residuos sólidos aprovechables.

El plan distrital de desarrollo para Bogotá 2016-2020 (Bogotá mejor para todos), por medio del Acuerdo 645 de 2016 de la Secretaría del Hábitat (2016, p. 9), "establece en los artículos 86, 87 y 88 directrices para la gestión integral de los residuos en la ciudad, la preservación de los recursos, la prestación de los servicios en condiciones de dignidad e igualdad, el consumo responsable y la producción sostenible". En particular, el plan enfatiza en la necesidad de aumentar el nivel de aprovechamiento de los residuos sólidos, superar el estado de vulnerabilidad de la población recicladora y ampliar la demanda de materiales reciclados. Al mismo tiempo, en el 2016 se lanza el Plan de Gestión Integral de Residuos Sólidos para Bogotá. En este documento se presenta el árbol de problemas y de objetivos en los aspectos institucionales, de recolección y transporte, aprovechamiento, inclusión de la población recicladora y disposición final entre otros.

En el gráfico 1 se muestra la manera como los operadores tenían, hasta comienzos de 2018, distribuida la prestación del servicio en las 19 localidades de la ciudad (no se incluye Sumapaz por ser eminentemente rural). A partir del 12 de febrero de 2018 se estableció un nuevo sistema de recolección de residuos sólidos. La ciudad se dividió en cinco áreas de servicio exclusivo (ASE) en las que operadores privados prestan el servicio de recolección y transporte de los residuos no aprovechables (tabla 1). 
María del Pilar Sánchez-Muñoz, José Gabriel Cruz Cerón y José Jardani Giraldo Uribe

Gráfico 1. Mapa de la prestación del servicio de aseo por localidades 2018

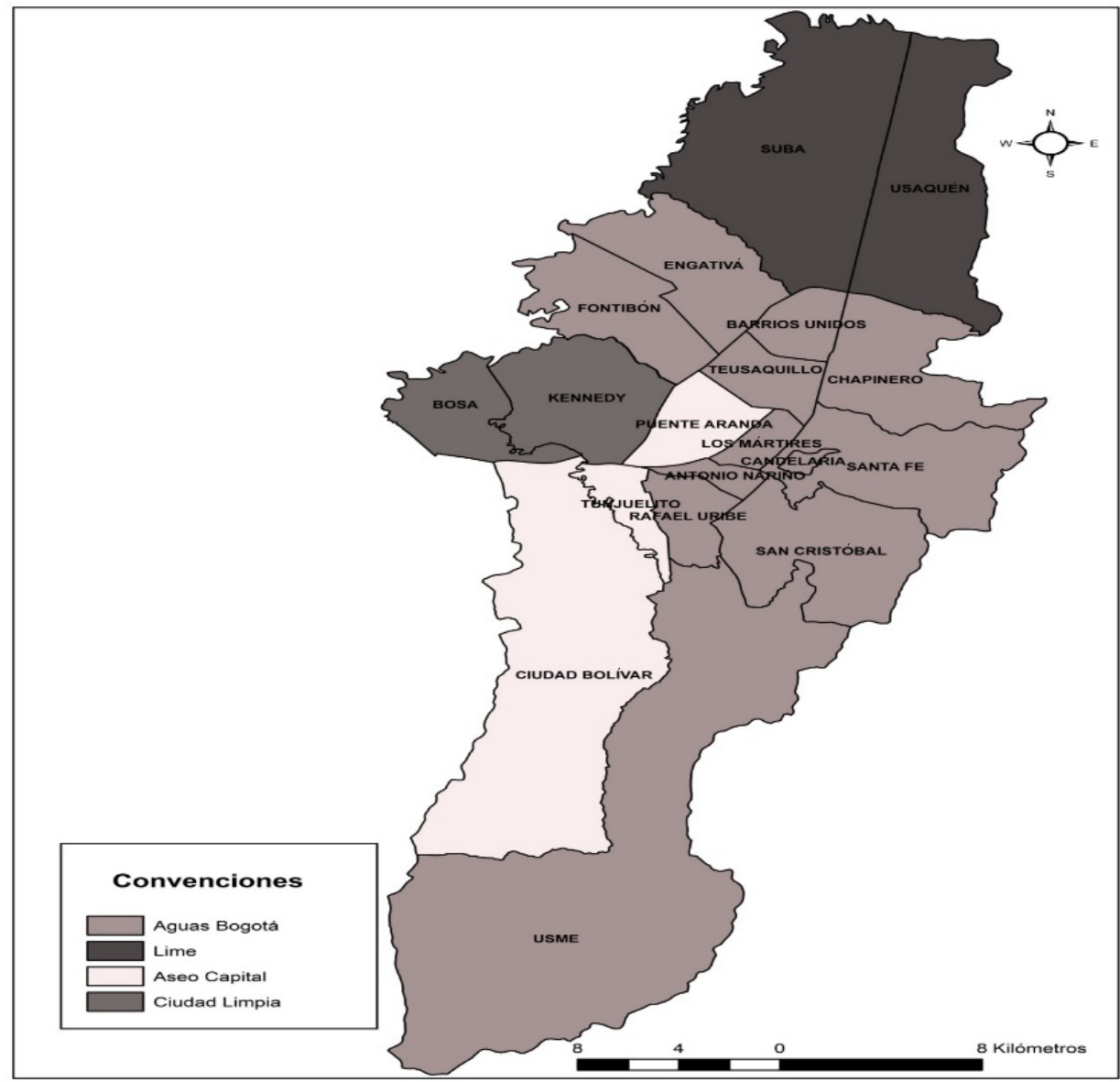

Fuente: elaboración propia a través de ArcGIS. 
Análisis de la opinión de los hogares sobre la gestión de los residuos sólidos domiciliarios en Bogotá

Tabla 1. Áreas de servicio exclusivo 2018

\begin{tabular}{cll}
\hline $\begin{array}{c}\text { Áreas de servicio } \\
\text { exclusivo (ASE) }\end{array}$ & \multicolumn{1}{c}{ Operador } & \multicolumn{1}{c}{ Localidades } \\
\hline 1 & Promoambiental Distrito S. A. ESP. & $\begin{array}{l}\text { Usaquén, Chapinero, Santa Fe, La } \\
\text { Candelaria, San Cristóbal, Usme y Sumapaz }\end{array}$ \\
\hline 2 & Lime S. A. ESP. & $\begin{array}{l}\text { Antonio Nariño, Bosa, Ciudad Bolívar, Los } \\
\text { Mártires, Puente Aranda, Rafael Uribe, Teusa- } \\
\text { quillo y Tunjuelito }\end{array}$ \\
\hline 3 & Ciudad Limpia de Bogotá ESP. & Kennedy y Fontibón \\
\hline 4 & $\begin{array}{l}\text { Promesa Sociedad Futura Bogotá } \\
\text { Limpia }\end{array}$ & Barrios Unidos y Engativá \\
\hline 5 & Área Limpia S. A. ESP. & Suba \\
\hline
\end{tabular}

Fuente: elaboración propia.

De acuerdo con información de la Secretaría del Hábitat, Uaesp (2017) , desde el 2018 se están implementando nuevos contenedores para la separación de residuos sólidos, se están ejecutando campañas de cultura ciudadana y se están poniendo en marcha las sanciones para quienes no reciclen. Se espera que los ciudadanos separen residuos que son aprovechables como el papel, el cartón y todo aquello que no esté contaminado, y los recicladores serán los únicos autorizados para realizar la recolección y aprovechamiento del material aprovechable, de acuerdo con las rutas y asociaciones correspondientes a cada área de servicio exclusivo (ASE). Se plantean canales de comunicación directa entre el operador y las organizaciones de recicladores.

De acuerdo con la línea base publicada en el Plan de Gestión Integral de Residuos Sólidos para la ciudad de Bogotá, los ciudadanos entre el 2013 y el 2014 generaron en promedio 0,30 toneladas de residuos sólidos domiciliarios por habitante. La tabla 2 muestra el comportamiento de la generación, disposición y aprovechamiento de residuos sólidos entre 2014 y 2016. Se puede ver que en la ciudad mientras en el 2014 se aprovechó el 12,8 \% de los residuos generados, en el 2015 aumentó al 14,8 \%, sin embargo, para el 2016 el aprovechamiento fue del 13,8\%. Se presenta, además, un decrecimiento de los residuos sólidos generados del 1,2 \% para el 2015 y de 2,5\% para el 2016, aspecto que es de destacar en la medida en que la población en la ciudad creció a una tasa de 1,3\%, durante esos años. 
María del Pilar Sánchez-Muñoz, José Gabriel Cruz Cerón y José Jardani Giraldo Uribe

Tabla 2. Generación, disposición y aprovechamiento de los residuos sólidos

\begin{tabular}{lccc}
\hline \multicolumn{1}{c}{ Residuos } & 2014 & 2015 & 2016 \\
\hline Residuos sólidos generados $(\mathrm{t})^{*}$ & 2.695 .307 & 2.662 .844 & 2.594 .978 \\
\hline Residuos sólidos dispuestos en relleno sanitario (t) & 2.351 .131 & 2.269 .533 & 2.253 .072 \\
\hline Residuos sólidos aprovechados (t) & 344.176 & 393.311 & 341.906 \\
\hline
\end{tabular}

* Corresponde a la suma de los residuos sólidos dispuestos y

los aprovechados

Fuente: Secretaría del Hábitat. Uaesp (2017).

En lo relacionado con las campañas dirigidas a la ciudadanía por parte de la entidad encargada, la Secretaría del Hábitat, Uaesp (2017) informó el número de usuarios sensibilizados sobre la importancia de hacer la separación en fuente y los efectos negativos de seguir disponiendo los residuos generados en el relleno sanitario (tabla 3).

Tabla 3. Usuarios sensibilizados

\begin{tabular}{|c|c|}
\hline Año & Usuarios \\
\hline 2013 & 718.084 \\
\hline 2014 & 662.144 \\
\hline 2015 & 284.800 \\
\hline 2016 & 44.347 \\
\hline
\end{tabular}

Fuente: Secretaría del Hábitat, Uaesp (2017).

En comparación con el número de habitantes que tiene la ciudad y el número de usuarios que reciben esta sensibilización, es indispensable aumentar las campañas en esta materia, porque los datos muestran una reducción significativa $(1.519,2 \%)$ entre el 2013 y el 2016 al pasar de 718.084 usuarios sensibilizados a 44.347.

\section{METODOLOGÍA}

Para el desarrollo de la investigación se realizaron 384 encuestas de opinión a los hogares bogotanos. Para ello, se seleccionaron las 12 localidades que recibieron el servicio de recolección de residuos sólidos por parte del operador público Aguas de Bogotá S. A. ESP. hasta el 11 de febrero de 2018; las cuales comprenden el 52 \% del territorio y abarcaban a 1.431 .744 suscriptores (gráfico 2). La ficha técnica para la recolección de la información se presenta en la tabla 4. 
Gráfico 2. Mapa de las áreas de recolección empresa Aguas de Bogotá S. A. ESP

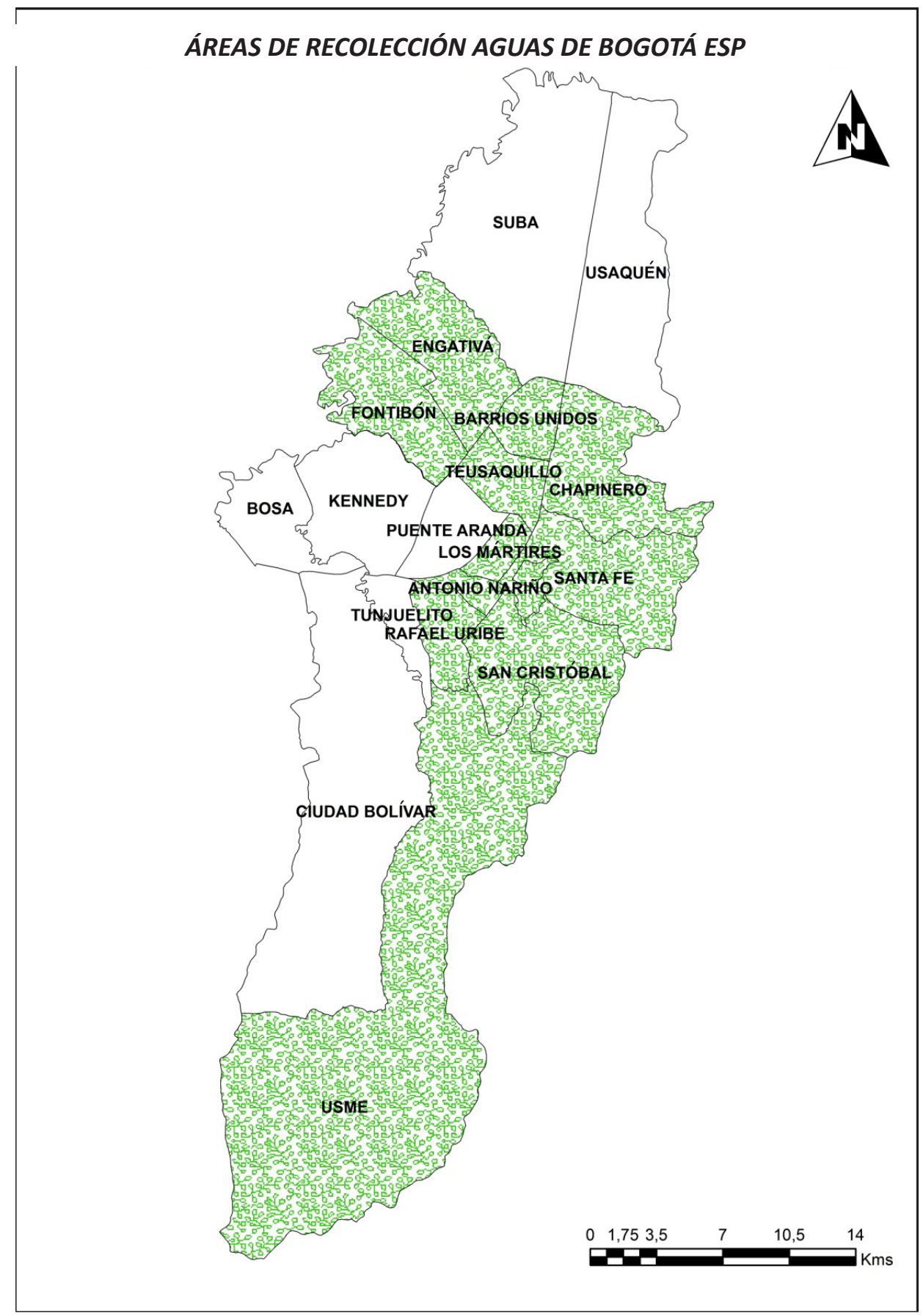

Fuente: elaboración propia a través de ArcGIS 
María del Pilar Sánchez-Muñoz, José Gabriel Cruz Cerón y José Jardani Giraldo Uribe

Tabla 4. Ficha técnica de la encuesta

\begin{tabular}{ll}
\hline Objetivo del estudio & $\begin{array}{l}\text { Identificar opiniones, actitudes y conocimientos de los hogares bogotanos } \\
\text { en } 12 \text { localidades, frente al manejo de residuos sólidos domiciliaros }\end{array}$ \\
\hline Grupo objetivo & Hogares \\
\hline Cubrimiento & $\begin{array}{l}\text { Doce localidades de Bogotá: Engativá, Fontibón, Barrios Unidos, Teusaquillo, } \\
\text { Chapinero, Los Mártires, Santa Fe, Antonio Nariño, Rafael Uribe Uribe, La } \\
\text { Candelaria, San Cristóbal y Usme }\end{array}$ \\
\hline Tipo de muestreo & Muestreo aleatorio estratificado \\
\hline Margen de error & \begin{tabular}{l}
$5 \%$ (nivel de confianza del 95\%) \\
\hline Medición
\end{tabular} \\
\hline $\begin{array}{l}\text { Fiveles máximos de } \\
\text { desagregación }\end{array}$ & Por estrato socioeconómico \\
\hline Total encuestados & 384 hogares \\
\hline Financiador & Personal \\
\hline
\end{tabular}

Fuente: elaboración propia.

La encuesta (anexo 1) tuvo 25 preguntas, divididas en cuatro módulos. El primero, con siete preguntas, intentó capturar la opinión de los encuestados sobre el tema. El segundo, indagó sobre los conocimientos que el encuestado posee (preguntas 8 a 11). El tercer módulo se centró en los aspectos de comportamiento y actitudes frente al manejo de residuos sólidos (preguntas 12 a 19). Finalmente, el último módulo (seis preguntas) se relacionó con algunos aspectos sociodemográficos de los encuestados. La encuesta se aplicó a la persona mayor de edad que se encontró en el hogar en el momento de la encuesta y que estaba en capacidad física y mental de contestarla.

De acuerdo con información catastral del año 2014, en Bogotá se encontraban registrados 1.985 .437 predios cuya finalidad es vivienda residencial permanente. De ellos, el 31,86 \% correspondientes a 632.546, están ubicados en las doce localidades en las que Aguas de Bogotá S. A. ESP., prestaba el servicio de recolección de residuos. La tabla 5 muestra cómo se encontraban distribuidos por estratos dichos predios.

Tabla 5. Suscriptores de la empresa Aguas de Bogotá S. A. ESP

\begin{tabular}{lccccccc}
\hline Estrato & 1 & 2 & 3 & 4 & 5 & 6 & Total \\
\hline Predios & 41.989 & 186.556 & 239.649 & 122.830 & 13.888 & 27.634 & 632.546 \\
\hline Proporción & $6,8 \%$ & $30,2 \%$ & $37,2 \%$ & $19,5 \%$ & $2,1 \%$ & $4,2 \%$ & $100 \%$ \\
\hline Muestra & 26 & 116 & 143 & 75 & 8 & 16 & 384 \\
\hline
\end{tabular}

Fuente: elaboración propia. Datos Catastro Distrital, 2014. 
Así, utilizando el método de muestreo estratificado proporcionado y manejando como variable de estratificación el estrato socioeconómico, con un nivel de confianza del $95 \%$, un error de ocurrencia del 0,5 y un error de estimación del $5 \%$, fue necesario aplicar 384 encuestas de opinión, distribuidas por estratos y por localidad como se muestra en la tabla 6.

La información recolectada fue triangulada con los criterios de análisis establecidos a partir de los referentes teóricos, asegurando la confiabilidad y el control de los errores de muestreo. Dentro del proceso de captura de información se realizaron las respectivas pruebas de verificación y consistencia del instrumento aplicado, manejando encuestas piloto y ensayos preliminares.

Tabla 6. Muestreo estratificado proporcionado

\begin{tabular}{|c|c|c|c|c|c|c|c|}
\hline \multirow{2}{*}{ Localidades } & \multicolumn{6}{|c|}{ Estrato } & \multirow{2}{*}{ Total } \\
\hline & 1 & 2 & 3 & 4 & 5 & 6 & \\
\hline Antonio Nariño & & 2 & 8 & & & & 10 \\
\hline Barrios Unidos & & & 7 & 7 & & & 14 \\
\hline Candelaria & & 2 & 1 & & & & 3 \\
\hline Chapinero & & 2 & 1 & 10 & 6 & 16 & 35 \\
\hline Engativá & & 18 & 63 & 6 & & & 87 \\
\hline Fontibón & & 10 & 24 & 23 & & & 57 \\
\hline Los Mártires & & 1 & 6 & 1 & & & 8 \\
\hline Rafael Uribe Uribe & 3 & 15 & 17 & & & & 35 \\
\hline San Cristóbal & 1 & 33 & 8 & & & & 42 \\
\hline Santa Fe & 3 & 9 & 6 & 2 & & & 20 \\
\hline Teusaquillo & & & 2 & 26 & 2 & & 30 \\
\hline Usme & 19 & 24 & & & & & 43 \\
\hline Total & 26 & 116 & 143 & 75 & 8 & 16 & 384 \\
\hline
\end{tabular}

Fuente: elaboración propia.

\section{RESULTADOS}

De las 384 encuestas aplicadas, el 45,3\% correspondió a hombres y el 54,7 \%, es decir 210, eran mujeres. Además, el 30,5 \% estaba en un rango de edad de 26 a 35 años y el 25,5\% entre 18 y 25 años. En casi todos los rangos de edad fue más la proporción de mujeres que contestaron el instrumento en comparación con 
los hombres, exceptuando las personas entre 56 y 65 años, en donde de las 24 encuestadas, 15 eran hombres.

\section{Gráfico 3. Nivel educativo}

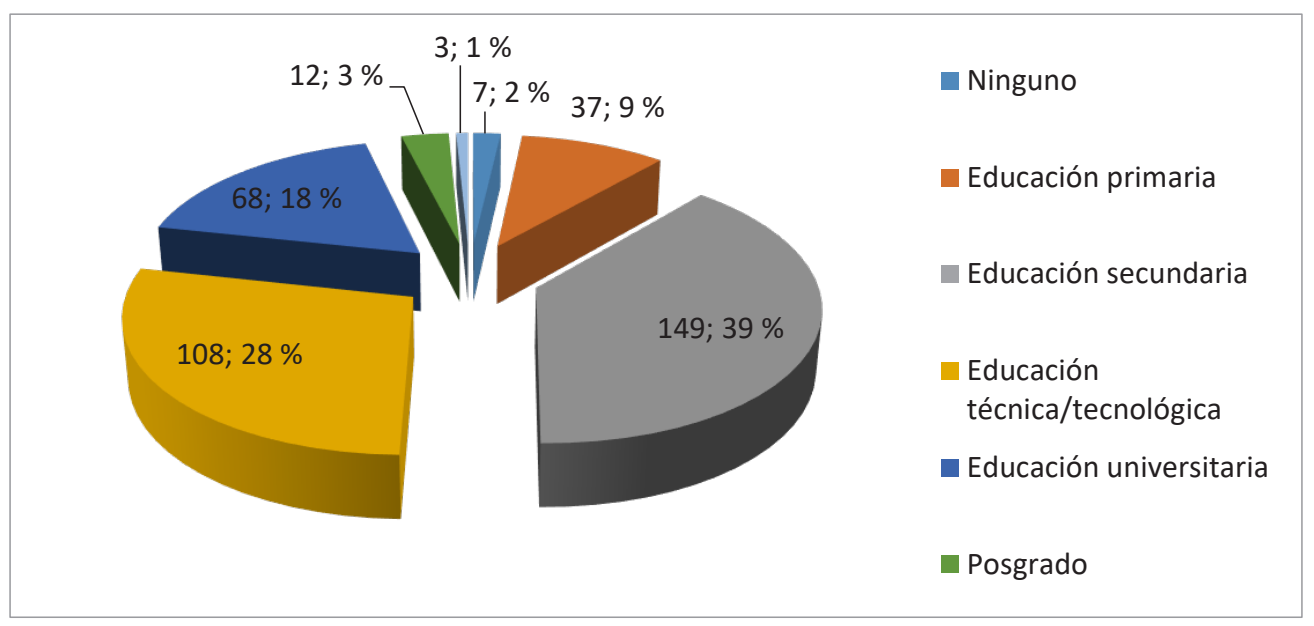

Fuente: elaboración propia.

El 48,4\% de los encuestados se encontraba trabajando en el momento en que se realizó la recolección de la información (primer semestre de 2017) y 103 personas estaban estudiando, correspondiente al 26,9\% de los 384 .

Con respecto al nivel de escolaridad, 149 personas (38,8 \% del total) tenían educación secundaria, 108 encuestados educación técnica y 68 educación universitaria, es decir el 17,7\%. Apenas el 3,1 \% (12 personas) tenían algún posgrado (gráfico 3).

En lo que respecta al nivel de ingresos el 72,1 \% recibía menos de un millón de pesos y tan solo cinco encuestados más de cuatro millones (gráfico 4).

\subsection{Desarrollo sostenible}

De los 384 encuestados, el 77 \% eran conscientes de la importancia de proteger el medio ambiente para mejorar la calidad de vida, lo que los motiva a preocuparse por el adecuado manejo de los residuos sólidos. Además, se encontró que el 17,2 \% de los encuestados se sentía poco o nada afectado por la inadecuada disposición de los desechos, mientras que 101 personas (26,3\%) respondieron sentirse muy afectados. Asimismo, 164 encuestados (42,7\%) se sintieron bastante afectados por la elevada producción de residuos sólidos. 


\section{Gráfico 4. Nivel de ingresos}

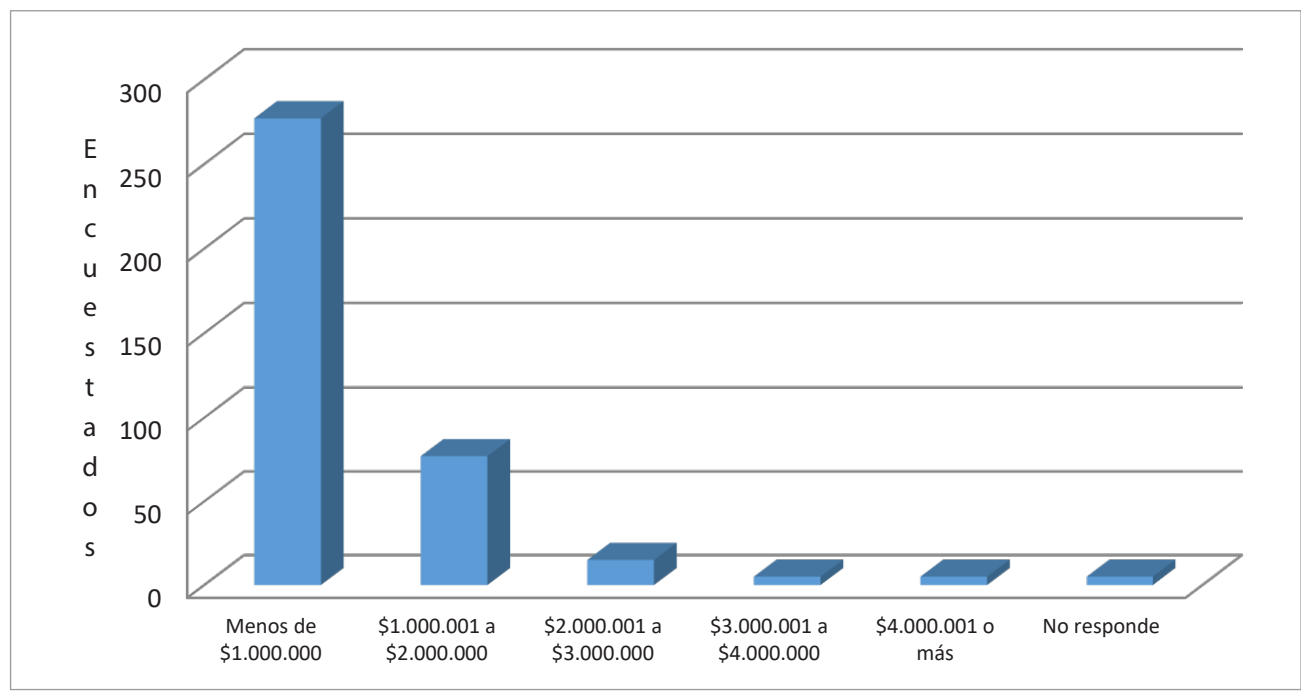

Fuente: elaboración propia.

Además, se encontró que 103 personas consideraban que las campañas pedagógicas sobre el manejo de residuos sólidos son masivas, sin embargo, no son efectivas para cambiar la actitud de los ciudadanos frente a sus decisiones de consumo y la separación en fuente. Por otro lado, solamente el 10,2 \% de los encuestados opinaron que no son masivas. El 68,5 \% de los encuestados (263 personas) consideró que las campañas de cultura ciudadana presentadas en el recibo del servicio de aseo, para aumentar la cantidad de material reutilizable en la ciudad son insuficientes. Por lo anterior, hace falta que las iniciativas de las campañas publicitarias provengan del sector público y no solo del sector privado.

Para aumentar el nivel de separación en la fuente, el país ha adoptado medidas como: la obligatoriedad de la separación en la fuente establecida en el Título 2 del Decreto 1077 de 2015; las campañas educativas en los niveles municipales y por parte de operadores y sector productivo y los incentivos a la separación en la fuente como el definido recientemente en el marco tarifario de aseo, Resolución CRA 720 de 2015. No obstante, no existe una campaña intensiva promovida por el nivel nacional de gobierno (Consejo Nacional de Política Económica y Social -Conpes-, 2016). Sin embargo, de acuerdo con los resultados se puede inferir que estas medidas no son conocidas por los hogares.

En el gráfico 5 se evidencia que el 18,8 \% de los encuestados no sabía que uno de los principales propósitos del reciclaje es el de reducir la cantidad de residuos 
sólidos que se depositan en el relleno sanitario Doña Juana. Esto puede ser explicado por la falta de efectividad de la publicidad y de las campañas para dar a conocer los objetivos de política pública, los efectos sobre el medio ambiente de la generación excesiva e inadecuada disposición de desechos y, mucho menos, los efectos positivos que podría generar una adecuada separación en la fuente. Sin embargo, un poco más del 80 \% conocía sobre las ventajas del reciclaje, tales como la reducción de los niveles de contaminación y la reutilización del material potencialmente aprovechable. Finalmente, el 71,6 \% estaba a favor del reciclaje dado que ayuda al crecimiento económico de la ciudad.

\section{Gráfico 5. Conocimientos sobre el reciclaje}

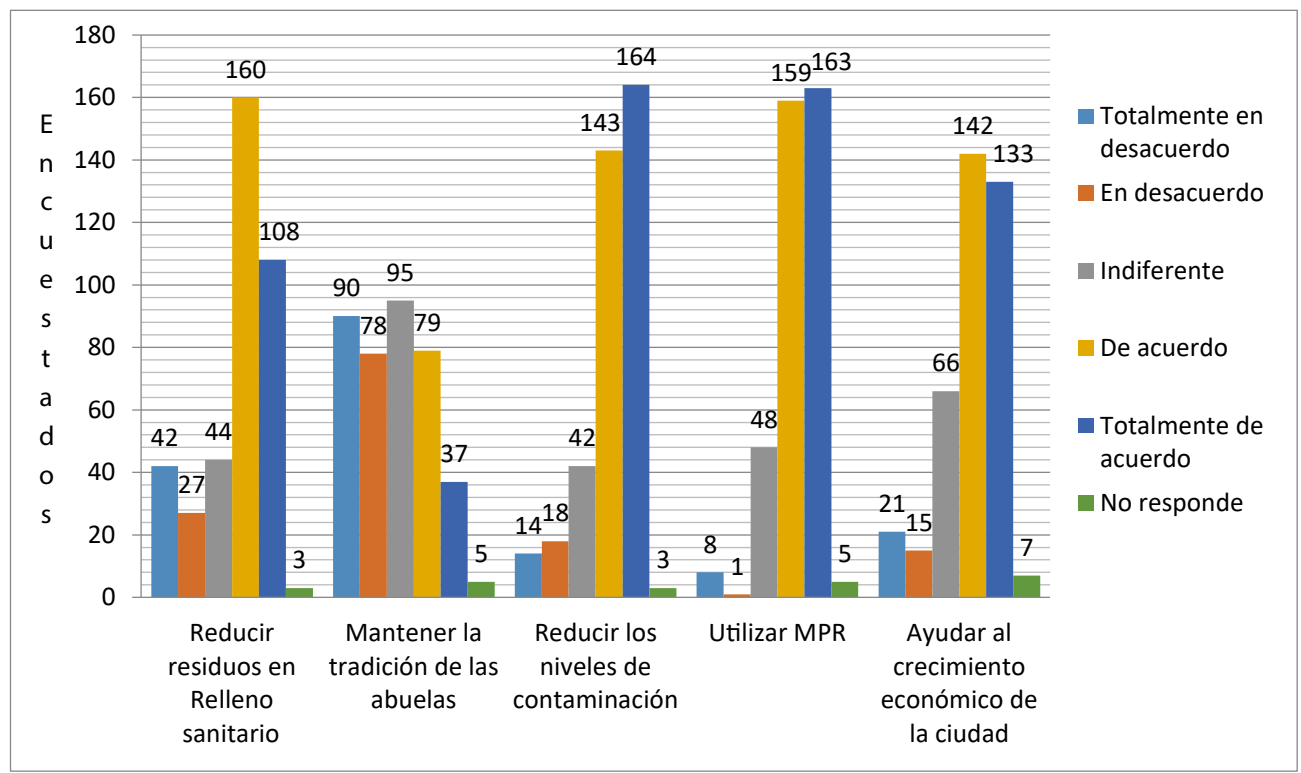

Fuente: elaboración propia.

Con respecto al conocimiento que los encuestados tenían sobre los mecanismos que existen en la ciudad para incentivar el reciclaje, el $52 \%$ de las personas no conocía la campaña para reducir el uso del pitillo; el 46,9 \% no sabía de la existencia de las máquinas que pagan por entregarle botellas de plástico y quienes no conocían sobre la existencia de Ecopuntos ${ }^{2}$ y la APP Recypuntos ${ }^{3}$ son más de la mitad, 66,7 \% y

2 Es una red de kioscos interactivos de reciclaje automático donde se ganan puntos por reciclar los envases de bebidas. Los puntos obtenidos se pueden canjear por boletos de cine y recargas de celular.

3 Es un aplicativo web y móvil con el cual los bogotanos pueden informarse acerca de las diferentes opciones que existen para disponer correctamente de todo tipo de residuos, tales como puntos de recolección, y programas autorizados para la gestión de los mismos, así como información educativa referente al proceso de aprovechamiento de residuos en general. 
83,6 \%, respectivamente. Se evidencia desinformación por parte de los encuestados. También se encontró que, aunque el Distrito Capital ha destinado recursos para sensibilizar a la población sobre la importancia de hacer separación en la fuente y el uso adecuado de los contenedores y de las bolsas plásticas, el 52,9 \% de los encuestados (200 personas) no ha participado en campañas educativas relacionadas con el tema. No obstante, si cerca de su vivienda o de su trabajo colocaran máquinas que pagan por el material reciclado, lo utilizarían 217 encuestados de los 384 (56,5\%).

Cabe resaltar que, del total de encuestados, el 47,4\% (182 personas) ha reducido el uso de bolsa plástica durante el último año. Apenas el 15,6 \% (60 encuestados) hace separación en la fuente, de los cuales el $40 \%$ se encontraba en un rango de edad entre 26 y 35 años; el 43 \% tenía educación secundaria y el 75 \% recibía menos de un millón de pesos mensuales.

También se pudo observar que de los 26 encuestados que vivían en estrato 1, el 42,3\% siempre separaba sus residuos orgánicos de los inorgánicos y de los 116 ubicados en estrato 2, el 31,9\% (37 personas) tenía esta práctica casi siempre. Paradójicamente, de los 16 encuestados en estrato 6, el 62,5 \% hacía separación de residuos solo a veces, y el 50 \% (4 entrevistados) de los de estrato 5, casi nunca. Se puede afirmar, siguiendo a Molina (2014), que no existe en la ciudad gobernanza ambiental porque los ciudadanos no están interesados en incurrir en los costos implícitos medidos en el tiempo que representa la separación, además la búsqueda de bienestar individual de corto plazo está por encima del bienestar colectivo.

\subsection{Territorio}

Con respecto al servicio recibido por los encuestados en materia de recolección de residuos sólidos, el 26,8 \% lo consideró malo, y solo dos personas lo calificaron como bueno. Además, 136 personas afirman que hacen falta ubicar contenedores en la ciudad para depositar los desechos debidamente separados y el 26,6\% que la tecnología actual de los carros recolectores de desechos no incentiva la separación de los mismos en el hogar. Se evidencian así problemas en la infraestructura de la ciudad para disponer los residuos sólidos en forma adecuada. Finalmente, el 28,9\% opinó que la frecuencia y los horarios de recolección de desechos en su barrio era adecuada.

De acuerdo con lo visto en otras ciudades del tamaño de Bogotá, se hace necesaria la construcción de puntos de transferencia y otros rellenos sanitarios, si tal es la tecnología de disposición con la que se va a cumplir el proceso. No obstante, al preguntarle a los encuestados si estarían dispuestos a aceptar cerca de su vivienda 
la apertura de un nuevo relleno sanitario o cualquier otra técnica de disposición de los desechos como la incineración, el 52,6 \% (202 personas) no lo aceptaría (gráfico 6). En contraposición, el 41,4 \% (159 encuestados) si estaría dispuesto a aceptar cerca de su vivienda la apertura de un centro de acopio de material reutilizable (bolsas, papel, vidrio, cartón, etc.). Esto evidencia un uso inapropiado del territorio y, siguiendo a Tello (2006), reduce las posibilidades de mejorar la calidad de vida de los habitantes.

\section{Gráfico 6. Aceptación de un nuevo relleno sanitario cerca de la vivienda}

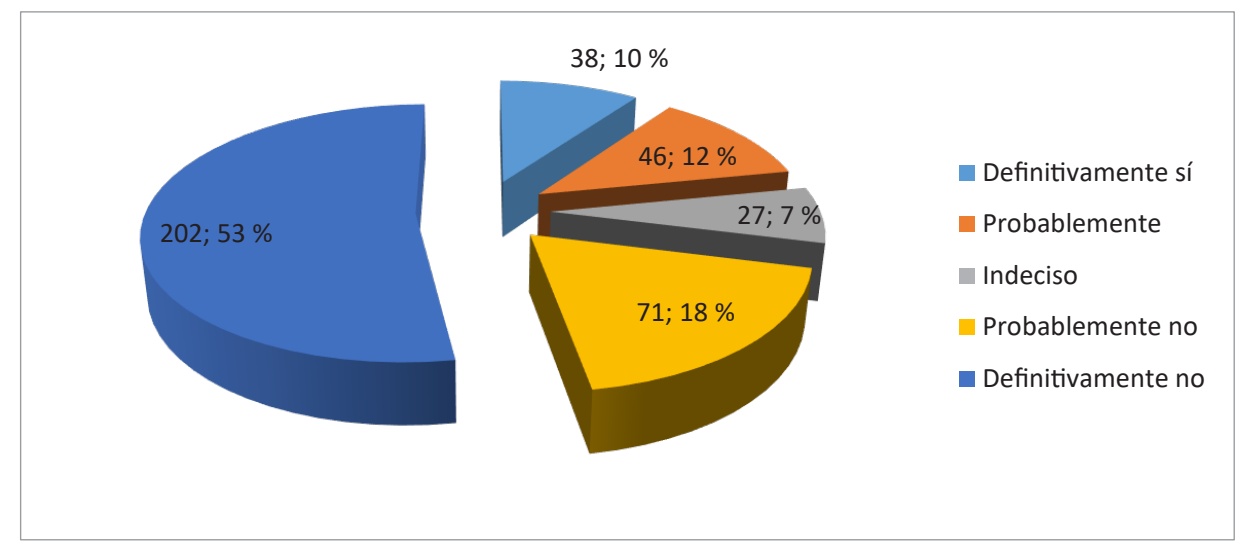

Fuente: elaboración propia.

\subsection{Instituciones}

Con el fin de mejorar la gestión de residuos sólidos es importante que los ciudadanos adquieran conciencia de la necesidad de cambiar algunas actitudes frente a la problemática. En este sentido, apenas 116 encuestados estaban totalmente de acuerdo con establecer como obligatoria la separación de los residuos sólidos, mientras que el 19,5\% estaba totalmente en desacuerdo.

En lo que respecta a las tarifas de aseo, el 47,7 \% consideró que las mismas incentivan el reciclaje, de las cuales 60 personas se encuentran entre los 26 y 35 años. Además, 223 encuestados pensaban que la mejor forma de incentivar la separación de basura en el hogar es multando a quien no lo hace, de estos, 85 tienen educación primaria. Otra regla de juego en el que el 63,3 \% está de acuerdo es que quien incumpla las normas actuales sobre el manejo de residuos, debería participar tanto en programas comunitarios como en actividades pedagógicas relacionadas, así como lo plantea el actual Código de Policía. 
En el caso de Colombia, la Resolución CRA 720 de 2015 incluyó dentro de la tarifa un incentivo al usuario por hacer el aprovechamiento de los residuos. No obstante, es necesario enfatizar que existe una relación directa entre la efectividad de la separación y la logística que exista para tal fin, es decir, el número de contenedores existentes, su ubicación, el número de rutas selectivas y la frecuencia de recolección de los residuos sólidos aprovechables.

Igualmente, se debe aprender de países como Holanda, un país con 6.467.000 habitantes, en donde se aplican tarifas en dos tramos. En dicho país, se paga por lo que se bota (Pay As You Throw, PAYT). En este sentido, si los ciudadanos no reciclan, la tarifa fija de recolección de residuos aumenta; adicionalmente, el reciclaje es gratis pero los ciudadanos pagan un impuesto (incluido en el valor de la bolsa) por los residuos sólidos que terminan siendo rechazados y llevados a la planta de incineración. Aproximadamente el 51 \% de lo generado es reciclado y el programa PAYT se ha traducido en un mayor aprovechamiento del material y una menor producción de material rechazado.

Las personas encuestadas tenían desconocimiento de algunas reglas de juego formales que existen, pero que no son divulgadas adecuadamente para que la sociedad se empodere de las mismas y empiece a actuar para su cumplimiento. Es así como el 68,8 \% no había escuchado hablar del Decreto 495 de 2016 con el cual se adopta el Plan Integral de Gestión de Residuos Sólidos, el 54,7 \% (210 personas) tampoco conocía la Resolución 0668 de 2016 sobre la prohibición de bolsas que tengan un tamaño menor a 30x30 y, aún más crítico, el desconocimiento (76,6 \% de los encuestados) de las estaciones de clasificación y aprovechamiento (ECAS), con las que cuenta la ciudad. Las sanciones establecidas en el nuevo Código Nacional de Policía en lo relacionado con los desechos eran conocidas por el 59,9\%. Lo anterior está relacionado, probablemente, con la difusión que se le hizo al Código en la televisión, las redes sociales y la radio, de hecho, 143 personas afirmaron haber conocido de este a través de la televisión.

No hay evidencia del efecto de la reducción en las tarifas sobre las acciones positivas de los encuestados en materia de manejo de residuos sólidos. De hecho, el 40,9 \% consideraba que dicha disminución los incentivaba, mientras el 43,8 \% plantea que no lo hacía. Definitivamente, se hace necesario un cambio de actitud por parte de los ciudadanos. En otras palabras, se requiere una política pública centrada en estrategias de cultura ciudadana para concientizar al ciudadano sobre la responsabilidad que tiene sobre sus residuos generados. 


\subsection{Gobernanza ambiental}

En el gráfico 7 se observa que el 31,3\% de los encuestados opinaron que los recicladores contribuyen bastante para lograr un manejo adecuado de los residuos sólidos, seguido por el 28,4\% quienes consideraban que los hogares también tienen un papel clave en esta tarea. Cabe destacar que el 23,7 \% no ven en las entidades de orden local ninguna contribución sobre el tema y el 22,7 \% tampoco se la dan a los medios de comunicación.

Se evidencia un problema sobre la apropiación del territorio y la actitud de no hacer nada frente a una práctica indebida como lo es la mala disposición de los residuos por parte de los vecinos, es así como frente a este evento el 48,2 \% de las personas encuestadas (185) no efectuó acto alguno, con argumentos como: no conocer mecanismos (72), el no tener tiempo (36), considerar que los instrumentos no tienen efecto (15) o simplemente no les interesa (12). De otro lado, tan solo 87 hicieron algo; de ellos el $30 \%$ intentó concientizar al otro que estaba realizando la actividad inadecuadamente y el 17,24 \% (15 encuestados) llamó a la policía. Se percibe entonces que el sentimiento de pertenencia de los ciudadanos por la ciudad es prácticamente inexistente.

Gráfico 7. Nivel de contribución de los actores para el adecuado manejo de los desechos

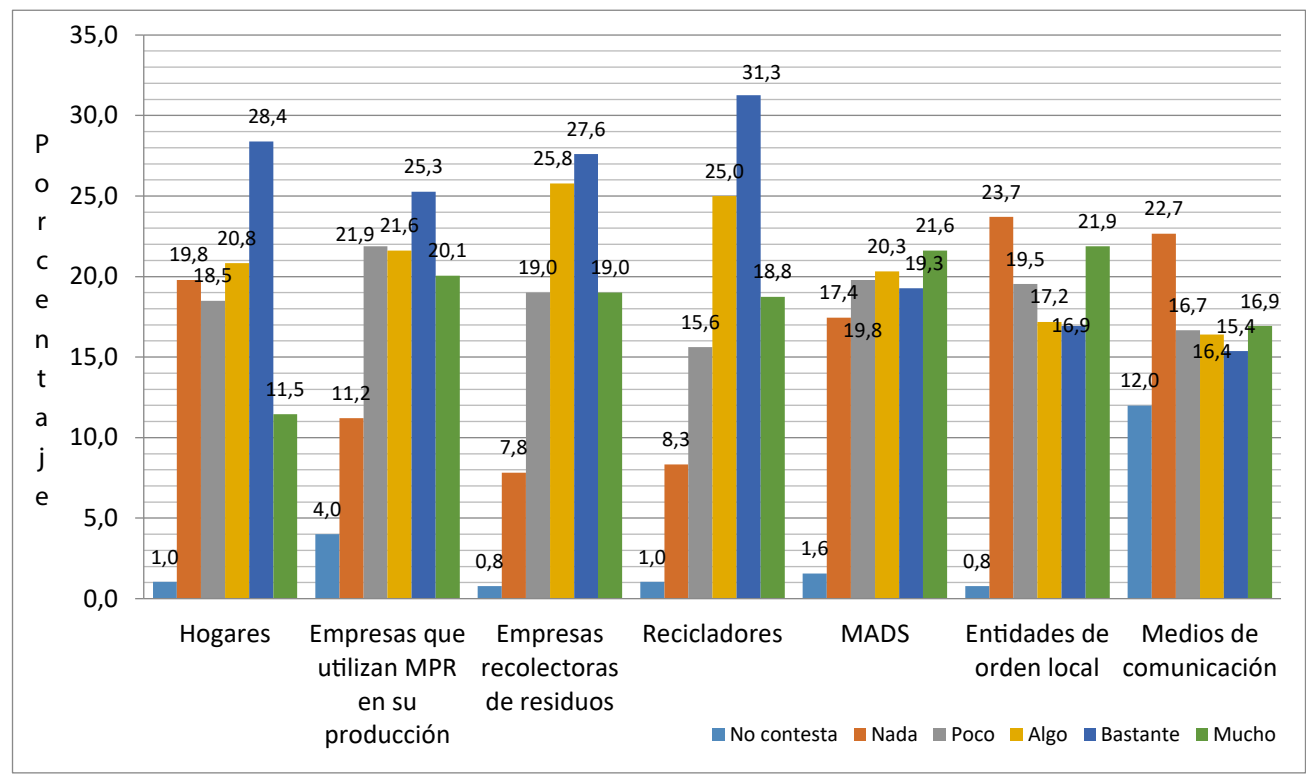

Fuente: elaboración propia. 


\section{CONCLUSIONES}

A partir de los resultados se puede concluir, con respecto al referente teórico del desarrollo sostenible, que la inadecuada disposición de residuos sólidos domiciliarios afecta significativamente al 26,3\% de las personas encuestadas, lo que se interpreta como una falta de interés en el tema. Se encontró que el estrato 3 es el más afectado, con un 63,6 \% de respuestas entre bastante y mucho. Con relación a la elevada producción de residuos, el 81,3 \% de los encuestados en el estrato 6, se sentían más afectado y el $87,5 \%$ de los de estrato 5 les molestaba bastante y mucho la presencia de habitantes de calle hurgando residuos. Los estratos 5 y 6 se sentían más afectados por el manejo de los residuos sólidos en comparación con el resto de estratos.

El 27,8 \% de los encuestados estaba de acuerdo con que las campañas pedagógicas eran masivas, pero que no llegaban a cambiar la actitud con respecto a la separación en la fuente y las decisiones de consumo de los habitantes. El 71,6 \% estaba a favor del reciclaje, pero no conocían sobre los mecanismos que existen en la ciudad para incentivar la actividad, evidenciándose el bajo nivel de efectividad de las campañas realizadas por parte de los operadores y de la administración distrital para mejorar el manejo de los residuos sólidos. Lo anterior está en contraposición con lo planteado por Novo $(2011)$ y Leff $(1995,2010)$, quienes subrayan la necesidad de adquirir conciencia sobre el consumo responsable y la separación en fuente para un mejor vivir.

Asimismo, los que más reciclaban eran los más jóvenes (de 26 a 35 años), los de menos ingresos (menos de un millón de pesos) y con un nivel de escolaridad medio. En cuanto al estrato socioeconómico, en la medida en que este aumentaba, disminuía la frecuencia de la separación en fuente. Los hallazgos son antagónicos frente a los planteamientos teóricos, dado que estos asumen que a mayor nivel de ingresos y con un nivel de escolaridad más alto, puede existir una mayor conciencia ambiental y unas prácticas más adecuadas para el manejo de los residuos sólidos.

Adicionalmente, es de vital importancia masificar las campañas de sensibilización sobre la separación en fuente y el uso adecuado de los contenedores y de las bolsas plásticas, para que se logre un cambio de actitud por parte de los ciudadanos. Igualmente, la transformación en los valores culturales debe trabajarse con más ahínco a través de la educación ambiental, enfocada en aquellos grupos poblacionales que no lo están haciendo.

En otras palabras, se requiere una política pública que involucre estrategias estructurales: de cultura ciudadana para concientizar al ciudadano sobre la respon- 
sabilidad que tiene sobre sus residuos generados; y de adecuación en mobiliario para que la actividad de reciclaje sea más eficiente, al disponer de espacios para su disposición, actividad que viene implementándose por la administración distrital 2016-2020.

Con respecto al territorio se concluye que existían problemas en la infraestructura, dado que, en el momento de la recolección de la información, no eran suficientes los contenedores instalados en la ciudad de Bogotá para depositar los desechos debidamente separados y el 58,6\% considera que la calidad del servicio es regular y mala. Desde el año 2018 se ha venido dotando a la ciudad de nueva infraestructura para la disposición de residuos de forma separada. De acuerdo con los hallazgos, y en coherencia con lo planteado por Molina (2013), se presentaba una tendencia a la falta de gobernanza ambiental, porque los ciudadanos no estaban interesados en incurrir en los costos implícitos medidos en el tiempo que representa la separación; además la búsqueda de bienestar individual de corto plazo estaba por encima del bienestar colectivo.

Con respecto a las instituciones se concluye que el $58 \%$ de los encuestados pensaba que la mejor forma de incentivar la separación de basura en el hogar es multando a quien no lo hace y el 63,3\% estuvo de acuerdo en establecer las actividades pedagógicas a infractores. No se encontró evidencia del efecto de la reducción en las tarifas sobre las acciones positivas de los encuestados en materia de manejo de residuos sólidos. Así, siguiendo a Monroy (2008) es necesario establecer unas reglas de juego claras y precisas para lograr el cambio de actitud por parte de los ciudadanos frente a la generación y disposición de los residuos sólidos. Las políticas ambientales deben buscar el buen manejo en la fuente de los residuos sólidos, la menor generación de estos residuos, la promoción de las políticas de producción limpia, un excelente nivel de recolección, transporte en vehículos modernos, buenas estaciones de transferencia y óptimos rellenos sanitarios.

En general, se puede afirmar que la estrategia para mejorar la gestión de los residuos sólidos debe ser integral, por ende, esta debe incluir elementos de carácter técnico e institucional, entendido esto último como unas reglas de juego claras y creíbles que incentiven realmente al ciudadano.

Con base en la investigación se sugieren como estrategias de política pública dirigidas a los hogares, un mayor mobiliario de canecas instalado por los operadores de recolección, y un incentivo por parte de la CRA en la tarifa para quienes hacen separación en la fuente o las sanciones para quienes no lo hagan. Cabe aclarar que la base del problema no es la separación en la fuente por sí sola. Lo es la dinámica 
del consumo del proceso capitalista y la falta de una política clara dirigida hacia la demanda, por lo que es imperante el cambio de paradigma del actual modelo de desarrollo. Por lo anterior, se requiere, además, de un aumento en el presupuesto que el Ministerio de Vivienda, Ciudad y Territorio destina a proyectos de ciencia, tecnología e innovación para agua y residuos sólidos, que es apenas del 0,13 \% en la actualidad, porque los retos del aprovechamiento pasan por lo técnico, lo administrativo, lo regulatorio hasta llegar a lo social.

Adicionalmente, es preciso que la educación ambiental trascienda hacia la cultura ambiental, para que las acciones de los actores redunden en una gestión de residuos sólidos coherente con la economía circular. Por ello, se requieren campañas educativas precisas, cortas y contundentes. Además, los planes de gestión integral de residuos sólidos deben ser vinculantes entre el Estado, la empresa privada y los ciudadanos. Debe ser el Estado quien realice el control y garantice el cumplimiento de la norma.

Las estrategias por si solas no serán efectivas si hacia el futuro sigue siendo más barato enterrar los residuos en vez de reciclarlos, si es más costoso cumplir la institucionalidad que no hacerlo (Martínez Alier y Roca, 2013), si no se desarrollan investigaciones de innovación tecnológica y social, si la logística para transportar los residuos sólidos aprovechables hacia la industria acarrea para esta última excesivos costos de transacción y si el sistema de información del sector sigue siendo deficiente.

\section{BIBLIOGRAFÍA}

Boisier, Sergio (1997). El vuelo de una cometa. Una metáfora para la teoría del desarrollo territorial. En: Estudios Regionales, n. ${ }^{\circ}$ 48, p. 41-79.

Boisier, Sergio (1999). Desarrollo local ¿De qué estamos hablando? En: Vásquez, Antonio y Madoery, Óscar (Eds.), Transformaciones globales, instituciones y políticas de desarrollo local. Rosario: Homo Sapiens, p. 48-74.

Carrasco, Roque Juan (2007). Región-territorio: planeación y ċdesarrollo sustentable? Planeación y desarrollo territorial. Ciudad de México: Instituto Politécnico Nacional, 232 p.

Cepal -Comisión Económica para América Latina y el Caribe (1994). Economía y Ecología: dos ciencias y una responsabilidad frente a la naturaleza. Lima: Cepal, $21 \mathrm{p}$.

Comisión Mundial sobre Medio Ambiente y el Desarrollo (1987). Nuestro futuro común. Oxford: Oxford University Press, 416 p.

Comisión Reguladora de Saneamiento Básico y Agua Potable. Colombia (2015). Resolución CRA 720 de julio 9 de 2015 por la cual se establece el régimen de regulación tarifaria al que deben someterse las personas prestadoras del servicio público de aseo que atien- 
dan en municipios de más de 5.000 suscriptores en áreas urbanas, la metodología que deben utilizar para el cálculo de las tarifas del servicio público de aseo y se dictan otras disposiciones, $64 \mathrm{p}$.

Concejo de Bogotá (2016). Acuerdo 645 de junio 9 de 2016 por el cual se adopta el Plan de Desarrollo Económico, Social, Ambiental y de Obras Públicas para Bogotá D. C. 2016-2020 Bogotá mejor para todos, $88 \mathrm{p}$.

Congreso de la República de Colombia (2015). Ley 1753 de junio 9 de 2015 por la cual se expide el Plan Nacional de Desarrollo 2014 - 2018 Todos por un nuevo país, 105 p.

Conpes -Consejo Nacional de Política Económica y Social (2016). Política nacional para la gestión integral de residuos sólidos. Recuperado de https://colaboracion.dnp.gov.co/CDT/Conpes/ Econ\%C3\%B3micos/3874.pdf

Gandlgruber, Bruno (2010). Instituciones, coordinación y empresas. Análisis económico más allá del mercado y Estado. Barcelona: Anthropos, 160 p.

Gómez, Hernando José, Director de la Misión de Crecimiento Verde del DNP (13 de Septiembre de 2017). Economía circular: estamos botando dinero a la caneca. (Diario Portafolio, Entrevistador) Bogotá. Obtenido de http://www.portafolio.co/economia/circular-estamos-botando-dinero-a-la-caneca-509684

Leff, Enrique (1995). ¿De quién es la naturaleza? Sobre la reapropiación social de los recursos

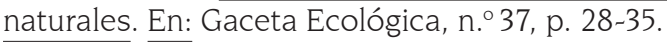

Leff, Enrique (2010). Saber ambiental: sustentabilidad, racionalidad, complejidad, poder. Ciudad de México: Siglo XXI, 141 p.

López, Adriana; Muñoz, Alcides; Cuesta, Andrés; Bohórquez, Camilo y Rendón, Jaime (2006). E desarrollo humano sostenible (DHS). Bases teóricas y prácticas para la implementación en la Universidad de La Salle. En: Revista de la Universidad de La Salle, n. ${ }^{\circ}$ 41, p. 79-87.

Martínez Alier, Joan y Roca, Jordi (2013). Economía ecológica y política ambiental. Ciudad de México: Fondo de Cultura Económica, 639 p.

Molina, Douglas (2013). Turismo rural y gobernanza ambiental: conceptos divergentes en países desarrollados y países en vías de desarrollo. En: Anuario Turismo y Sociedad, vol. 14, p. $217-235$.

Molina, Douglas (2014). Gobernanza ambiental en Colombia: la acción estatal y de los movimientos sociales. En: Ambiente y Desarrollo, vol. 18, n. 34, p. 27-42.

Monroy, Juan Carlos (2008). Políticas ambientales para los centros urbanos de Colombia. En: Rodríguez, Gloria Amparo, Londoño, Beatriz y Herrera, Giovanni (Eds.), Ciudades ambientalmente sostenibles. Bogotá: Universidad del Rosario, p. 70-97.

Novo, María (2011). La educación ambiental en tiempos de crisis. En: Transatlántica de Educación, vol. 6, n. 9, p. 8-13.

North, Douglass (1993). Instituciones, cambio estructural y desempeño económico. Ciudad de México: Fondo de Cultura Económica, 189 p. 
Organización de las Naciones Unidas (2017). Objetivo 6: Agua limpia y saneamieto. Programa de las Naciones Unidas para el Desarrollo. Disponible en: https://www.undp.org/content/ undp/es/home/sustainable-development-goals/goal-6-clean-water-and-sanitation.html

Panayotou, Theodore (1996). Ecología-economía, medio ambiente y desarrollo. En: Revista Corpoica. Ciencia y Tecnología Agropecuaria, vol. 1, n. ${ }^{\circ}$ 1, p. 40-45.

Presidencia de la República de Colombia (2015). Decreto 1077 de mayo 26 de 2015 por medio del cual se expide el Decreto único reglamentario del sector vivienda, ciudad y territorio, $806 \mathrm{p}$.

Portafolio (2017). Economía circular: estamos botando dinero a la caneca, Colombia, 1 p.

Sadeghian, Nastaran; Saman, Mir; Aliahmadi, Alireza y Jabbarzadeh, Armín (2018). A bi-level programming approach to joint network design and pricing problem in the municipal solid waste management system: A case study. En: Resources, Conservation y Recycling, vol. 131, p. 17-40. Doi: 10.1016/j.resconrec.2017.12.008

Sánchez, María del Pilar y Usaquén, Martha Inés (2012). Economía de los servicios públicos domiciliarios, más allá del mercado y del Estado. En: Revista Equidad y Desarrollo, n. ${ }^{\circ}$ 17, p. 31-56. Doi: 10.19052/ed.66

Secretaría del Hábitat de la Alcaldía Mayor de Bogotá. Colombia, Unidad Administrativa Especial de Servicios Públicos -Uaesp- (2017). Respuesta a derecho de petición radicado número 1-2017-06104 de febrero 3 de 2017, 4 p.

Secretaría del Hábitat de la Alcaldía Mayor de Bogotá. Colombia, Unidad Administrativa Especial de Servicios Públicos -Uaesp- (2016). Plan de Gestión Integral de Residuos Sólidos -PGIRS, $223 \mathrm{p}$.

Tello, Mario (2006). Las teorías del desarrollo local y la teoría y práctica del proceso de descentralización en los países en desarrollo. Lima: Pontificia Universidad Católica del Perú, 124 p.

Vergara, Rubén Alfonso (2014). Debates Contemporáneos sobre gobernanza: aproximaciones prácticas en Bogotá D. C. (1991-2014). En: Rendón, Jaime (Comp.). Estudios sobre desarrollo y planeación en Colombia. Bogotá: Mímeo, p. 89 - 122.

Villanueva, Carmen (2011). Educación Ambiental para la responsabilidad. En: Transatlántica de Educación, vol. 6, n. 9 9, p. 29-35.

Zhang, Yi; Huang, Guo y He, Li (2011). An inexact reverse logistics model for municipal solid waste management systems. En: Journal of Environmental Management, vol. 92, n. ${ }^{\circ}$ 3, p. 522-530. Doi: 10.1016/j.jenvman.2010.09.011 



\section{ANEXO 1 \\ ENCUESTA SOBRE EL MANEJO DE RESIDUOS SÓLIDOS}

Investigación: modelo socioecológico para los residuos sólidos domiciliarios aprovechables en Bogotá D. C.

Objetivo: analizar los componentes del manejo de residuos sólidos en la capital y así proponer acciones que mejoren el medio ambiente y las condiciones socioeconómicas de todos los habitantes de la ciudad.

Nombre:

Dirección:

Teléfono fijo o celular para efectos de verificación:

1. ¿Qué tan afectado se siente usted por las siguientes circunstancias?

\begin{tabular}{|c|c|c|c|c|}
\hline & Nada & Poco & Algo & Bastante \\
\hline Inadecuada disposición de desechos & & & & \\
\hline Elevada producción de basura & & & & \\
\hline $\begin{array}{l}\text { esencia de habitantes de calle } \\
\text { argando los residuos }\end{array}$ & & & & \\
\hline
\end{tabular}

2. ¿Cuál cree usted es el nivel de contribución de los siguientes actores para lograr el adecuado manejo de los desechos?

\begin{tabular}{l|l|l|l|l|l|} 
Hogares & \\
Empresas que utilizan material reciclado en su \\
proceso de producción \\
Empresas recolectoras de residuos
\end{tabular}


3. El servicio de recolección de residuos sólidos en su barrio es:

Malo

Regular

Bueno

Muy bueno

Excelente

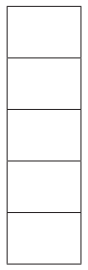

4. Marque en la casilla de acuerdo con su punto de vista:

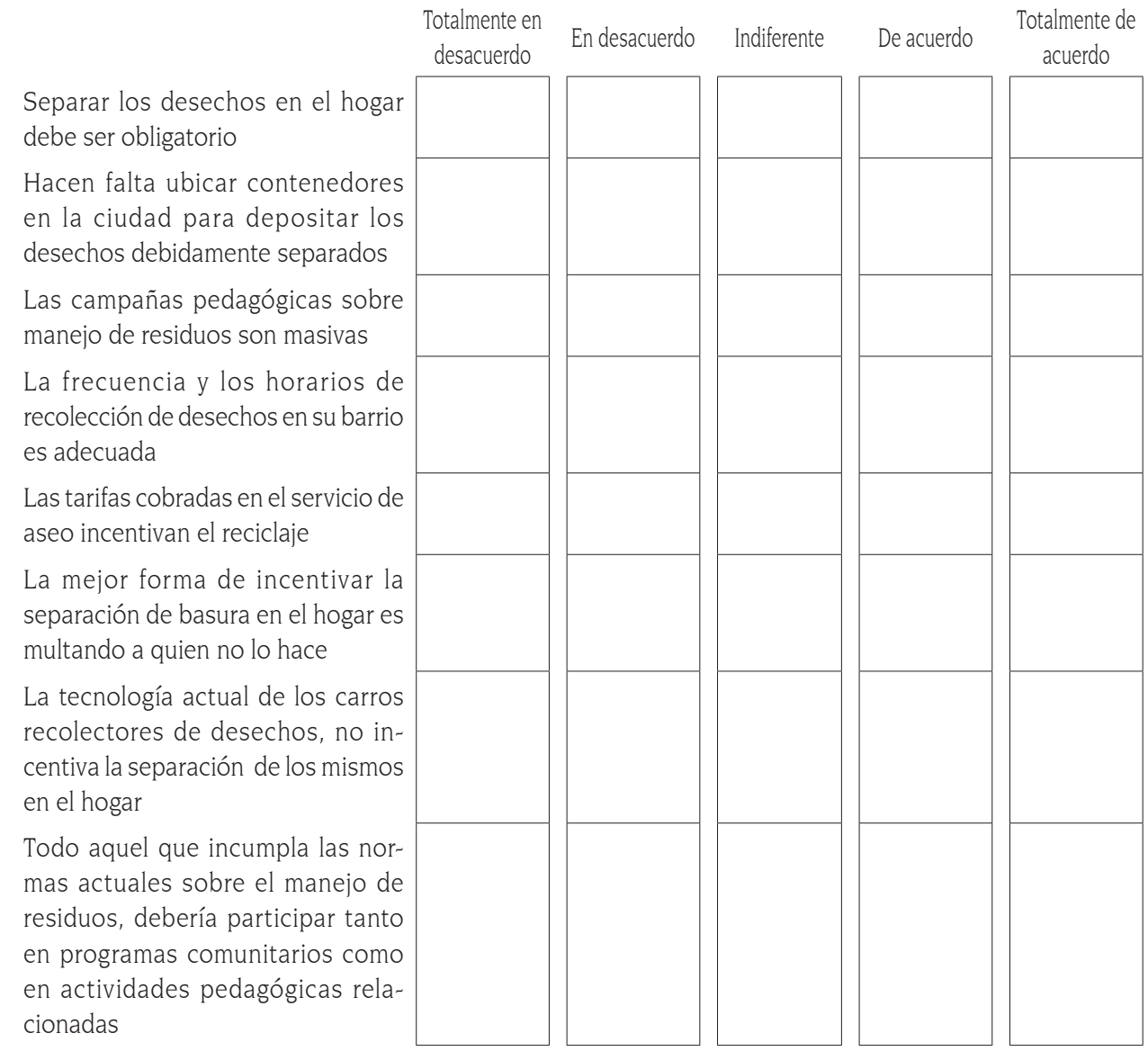

5. Considera que la campaña de cultura ciudadana, presentada en el recibo del servicio de aseo, para aumentar la cantidad de material reutilizable (bolsas, papel, vidrio, cartón, etc.) en la ciudad, es:

Suficiente

Insuficiente

No sabe

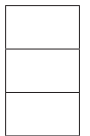


6. En una escala de 1 a 5, siendo 1 (aburrida, inútil o innecesaria) y 5 (amena, útil o necesaria), considera que la campaña de reciclaje utilizada en Bogotá, en el último año, es:

Aburrida

Inútil

Innecesaria

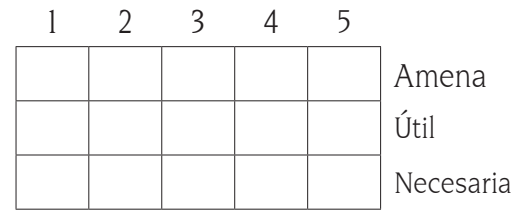

7. ¿Qué estrategia considera se debe adoptar para que la reducción de residuos sólidos generados y el aprovechamiento de material potencialmente reutilizables se logren eficazmente?

8. El principal propósito de reciclar es:

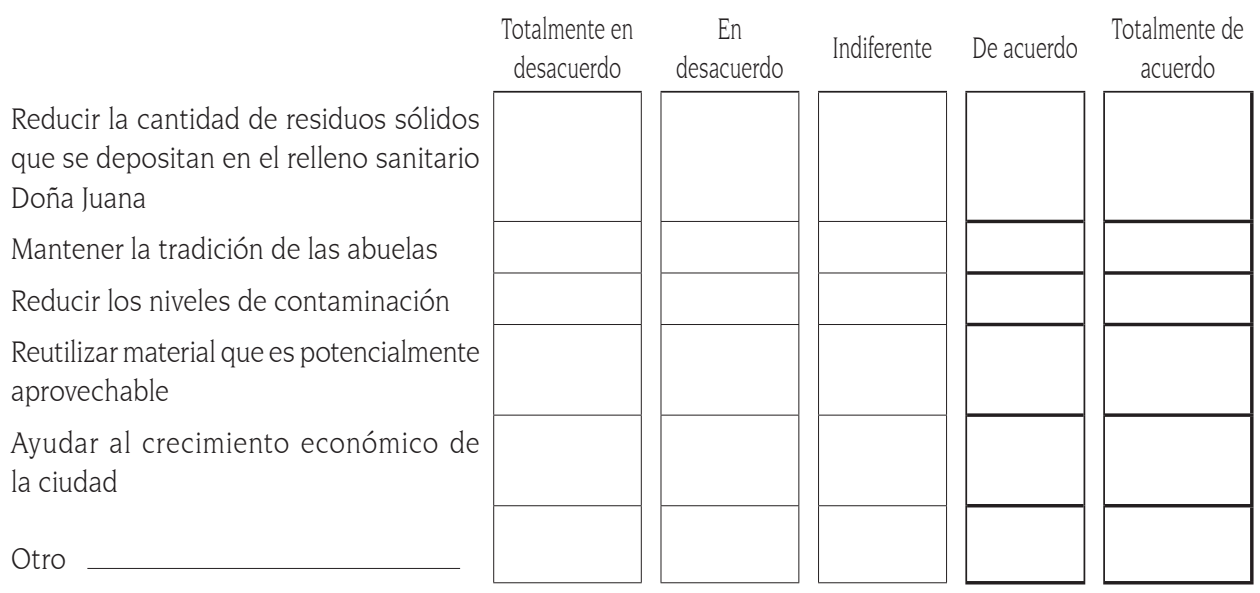

9. ¿Ha escuchado hablar de los siguientes mecanismos que existen para incentivar el reciclaje?

Las máquinas que pagan por reciclar botellas de plástico

Las campañas para reducir el uso del pitillo

La existencia de Ecopuntos

La APP Recypuntos

Otro

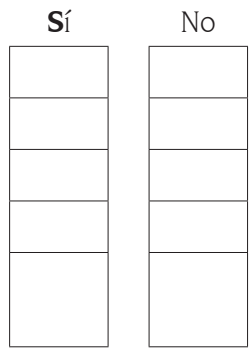


10. ¿Ha escuchado hablar de las siguientes acciones/normas que se están implementando en la ciudad, en relación con el manejo de desechos?

El Decreto 495 de 2016 con el cual se adopta el Plan Integral de Gestión de Residuos
Sólidos
La Resolución 0668 de 2016 sobre la prohibición de bolsas que tengan un tamaño
menor a 30x30
Las sanciones establecidas en el nuevo Código Nacional de Policía en lo relacio-
nado con los desechos
Las estaciones de clasificación y aprovechamiento (ECAS), con las que cuenta
la ciudad

11. ¿En qué canal de comunicación conoció sobre los temas anteriores?

Televisión

Internet (página web, redes sociales)

Radio

Revistas

Otro

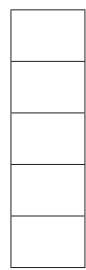

12. Cuando presenció a alguien disponiendo los desechos inadecuadamente, usted:

No hizo nada

Hizo algo

No ha presenciado actuaciones inadecuadas de disposición

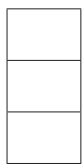

13. En caso de haber hecho algo, esto fue:

Firmó una carta en contra

Apoyó una campaña en contra a través de redes sociales (ejemplo: Facebook, Twitter, Instagram)

Protestó (marchas, plantones, etc.)

Participó como activista en una campaña en contra

Mandó correos electrónicos en contra

Intentó concientizar a la(s) persona(s)

Llamó a la policía

Otra

No responde

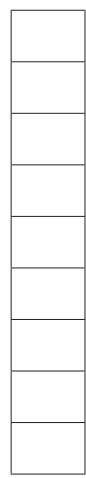


14. Si no hizo nada frente a la inadecuada disposición de residuos fue porque:

No conoce mecanismos o formas para actuar frente a estas situaciones

No tiene tiempo

No le interesa

Cree que ninguno de los instrumentos existentes tengan un efecto verdadero

No tiene incentivos

Otra

No responde

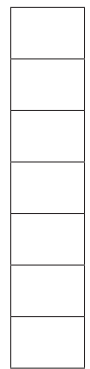

15. Durante el último año, ha implementado acciones relacionadas con el manejo de residuos sólidos, tales como:

Reducir el uso de bolsas plásticas

Disponer los desechos separadamente entre orgánicos e inorgánicos

Reutilizar material como papel, plástico y vidrio

Llevar las pilas usadas a los contenedores especiales ubicados en diferentes puntos de la ciudad

Disponer las bombillas usadas en los contenedores especiales ubicados en diferentes puntos de la ciudad Sacar la basura en horarios autorizados por la empresa prestadora del servicio

Usar los contenedores dispuestos cerca a su casa para depositar los desechos generados

Participar en campañas de educación sobre separación de residuos sólidos o sobre temas relacionados

Otra

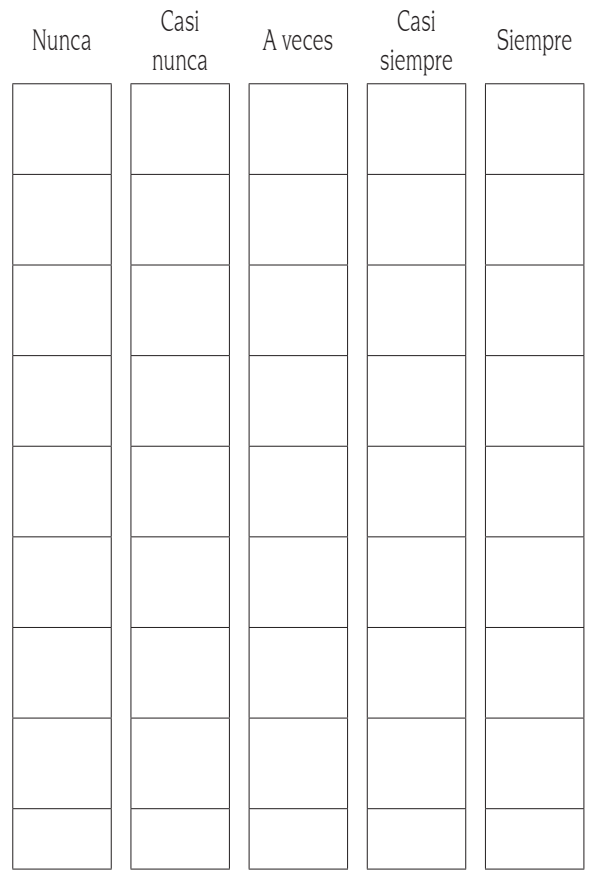

16. ¿Qué lo ha motivado a implementar las acciones anteriores?

Sí

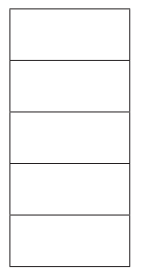

No

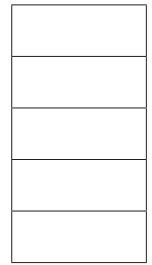

No sabe/no responde

Reducción en el pago del servicio de aseo

Considera importante proteger el medio ambiente Mejora la calidad de vida de su entorno

Exigencia de familiares, amigos o vecinos

Otra 
17. Si cerca de su vivienda o lugar de trabajo ubicaran máquinas que pagan por el material reciclado que usted deposite, ¿utilizaría dichas máquinas?

Definitivamente sî

Probablemente

Indeciso

Probablemente no

Definitivamente no

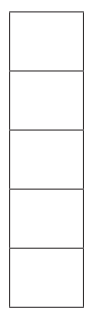

18. ¿Estaría usted dispuesto a aceptar cerca de su vivienda la apertura de un centro de acopio de material reutilizable (bolsas, papel, vidrio, cartón, etc.)?

Definitivamente sî

Probablemente

Indeciso

Probablemente no

Definitivamente no

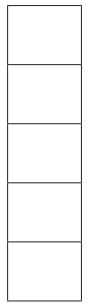

19. ¿Estaría usted dispuesto a aceptar cerca de su vivienda la apertura de un nuevo relleno sanitario o cualquier otra técnica de disposición de los desechos como la incineración?

Definitivamente sí

Probablemente

Indeciso

Probablemente no

Definitivamente no

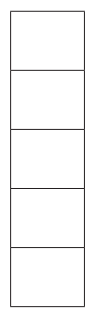

20. Su edad se encuentra en el rango de

18 a 25 años

26 a 35 años

36 a 45 años

46 a 55 años

56 a 65 años

Más de 65 años

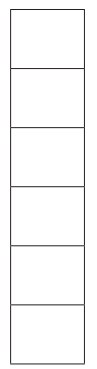


21. ¿Cuál es su parentesco con el jefe de hogar?

Jefe

Cónyuge

Hijo (a)

Otro

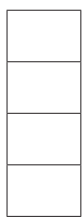

22. ¿Cuál es su nivel educativo más alto alcanzado?

Ninguno

Educación primaria

Educación secundaria

Educación técnica/tecnológica

Educación universitaria

Posgrado

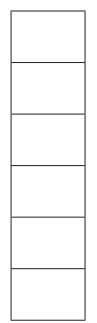

23. ¿Qué hace usted principalmente?

Trabajar

Oficios del hogar sin remuneración

Estudiar y trabajar

Pensionado

Estudiar

Estar desempleado en busca de un trabajo

No responde

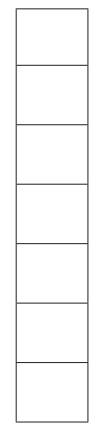

24. ¿Cuántas personas usted tiene a cargo?

25. Su nivel de ingresos mensual se encuentra entre:

Menos de $\$ 1.000 .000$

$\$ 1.000 .001$ a $\$ 2.000 .000$

$\$ 2.000 .001$ a $\$ 3.000 .000$

$\$ 3.000 .001$ a $\$ 4.000 .000$

$\$ 4.000 .001$ o más

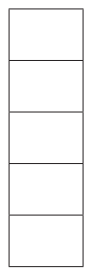

